\title{
PELATIHAN PENGAMAN INSTALASI LISTRIK SESUAI PERSYARATAN UMUM INSTALASI LISTRIK 2011 SERTA AMANDEMEN 2014
}

\author{
I.B.A. Swamardika ${ }^{1}$, A.A.N. Amrita ${ }^{2}$, I.G.D. Arjana $^{3}$ dan C.G.I. Partha ${ }^{4}$
}

\begin{abstract}
ABSTRAK
Listrik merupakan kebutuhan yang sangat vital bagi kehidupan masyarakat sekarang ini. Listrik menjadi kebutuhan primer karena selain harganya relatif murah juga sangat membantu dalam kehidupan sehari-hari. Selain listrik mempunyai keuntungan yang sangat besar, listrik juga mempunyai bahaya yang dapat mengakibatkan kecelakaan seperti tersengat arus listrik, kebakaran dan kerusakan peralatan listrik.

Bahaya listrik dapat dihilangkan dengan mengikuti semua persyaratan-persyaratan instalasi listrik. Bahaya sengatan listrik dan kebakaran dapat di atasi dengan pengaman instalasi listrik yang tertuang dalam Persyaratan Umum Instalasi Listrik 2011 (PUIL 2011serta Amandemen tahun 2014, yang mengisyaratkan untuk mengamankan lingkungan dalam hal ini mengamankan manusia, wajib menggunakan pengaman instalasi listrik sesuai pengaman dengan Standar Nasional Indonesia (SNI).

Dalam pengabdian ini akan diberikan penjelasan dan pelatihan instalasi listrik yang sesuai dengan Persyaratan Umum Instalasi Listrik bagi masyarakat di Desa Sinduwati, Kecamatan Sidemen, Kabupaten Karangasem
\end{abstract}

Kata kunci : Listrik, Instalasi, Pengaman, PUIL, Kebakaran.

\begin{abstract}
Electricity is a very vital needs for the life of the community it is today. Electricity became the primary needs of the relatively inexpensive price because in addition is also very helpful in everyday life. In addition to electricity has huge advantages, electricity also has a hazard that can lead to accidents such as fire, electrical current was stung and damage electrical equipment.

Electrical hazards can be eliminated by following all electrical installation requirements. Danger of electric shock and fires can be corrected with electrical installation safety contained in the 2011 electrical installation General requirements (Amendment 2011serta year 2014 PUIL, who hinted to secure the environment in this securing human safety, mandatory use of electrical installation in accordance with the National Standard safety Indonesia (SNI).

In this devotion will be given an explanation and electric installation training in accordance with the General requirements of the electrical installation for the community in the village of Sinduwati, district Sidemen Karangasem Regency
\end{abstract}

Keywords: Electricity, Installation, Security, PUIL, Fire.

\footnotetext{
${ }^{1}$ Staf Pengajar Jurusan Teknik Elektro Fakultas Teknik Universitas Udayana, gusalit@ee.unud.ac.id.

${ }^{2}$ Staf Pengajar Jurusan Teknik Elektro Fakultas Teknik Universitas Udayana, budiastra@ee.unud.ac.id

${ }^{3}$ Staf Pengajar Jurusan Teknik Elektro Fakultas Teknik Universitas Udayana, ngramrita@ee.unud.ac.id

${ }^{4}$ Staf Pengajar Jurusan Teknik Elektro Fakultas Teknik Universitas Udayana, cokindra@ee.unud.ac.id
} 


\section{PENDAhUluan}

Kecelakaan akibat penggunaan energi listrik seperti tersengat arus listrik, kebakaran dan kerusakan peralatan listrik sering terjadi di masyarakat, hal ini memicu kami untuk membuat pengabdian kepada masyarakat ini dengan tujuan agar masyarakat dapat mencegah kecelakaan akibat penggunaan energi listrik tersebut. Kecelakaan-kecelakaan tersebut sering disebabkan oleh Instalasi listrik yang tidak baik. Untuk kecelakaan tersengat arus listrik umumnya kurangnya isolasi penghantar serta pengaman yang digunakan, sedangkan untuk kecelaan kebakaran terjadi karena hubungan pendek atau konsleting listrik, beberapa peralatan listrik yang rentan terhadap hubungan pendek seperti kabel listrik, pemakaian kabel yang tidak sesuai dengan peruntukannya menyebabkan terbakarnya lapisan pembungkus kabel.

Pemasangan/penyambungan peralatan-peralatan listrik ini banyak dijumpai hal-hal yang tidak memenuhi pemasangan yang benar dan tidak sesuai dengan aturan, seperti menggunakan isolasi seadanya atau bahkan plastik yang digunakan untuk mengisolasi sambungan kabel, umur kabel yang sudah kelihatan lama dan rapuh, luas penghantar yang tidak sesuai dengan beban dari peralatan yang terpakai, pemasangan pada kotak kontak yang sangat banyak dan melebihi kapasitasnya.

Desa Sinduwati, Kecamatan Sidemen-Karangasem, penduduknya sudah menggunakan energi listrik yang kian hari kebutuhan energi listrik kian. Energi listrik ini sangat bermanfaat bagi kehidupan kita semua, tetapi energi ini juga sangat berbahaya terhadap lingkungan kalau tidak diamankan dengan baik.

Berdasarkan situasi diatas maka dipandang perlu untuk dilaksanakan "Pelatihan Pengaman Instalasi Listrik Sesuai Persyaratan Umum Instalasi Listrik 2011 Serta Amandemen 2014 Di Desa Sinduwati, Kecamatan Sidemen-Karangasem".

Rumusan masalah dalam pengabdian masyarakat ini adalah bagaimana pemasangan dam pengamanan energi listrik sesuai dengan Persyaratan Umum Instalasi Listrik untuk mencegah bahaya kecelakaan akibat listrik?

\section{MATERI DAN METODE}

Permasalah yang utama juga adalah pengetahuan masyarakat tentang pemasangan peralatan dan instalasi listrik sangat minim/kurang, sehingga masyarakat hanya mengandalkan cara pemasangan yang tidak memenuhi standar dan yang terpenting untuk sementara adalah bisa beroperasinya peralatan-peralatan (nyala) yang memerlukan energi listrik Seperti ditunjukan pada gambar 2.1, dimana penyambungan kabel di isolasi dengan bahan plastik seadanya, sedangkan lingkungan sekitarnya terbuat dari logam yang bisa menghantarkan listrik dan bahan-bahan yang mudah terbakar. Begitu pentingnya energi listrik dan keterbatasan pengetahuan dasar tentang pemakaian dan pemasangan listrik menjadi penyebab utama terjadinya kegagalan instalasi listrik.
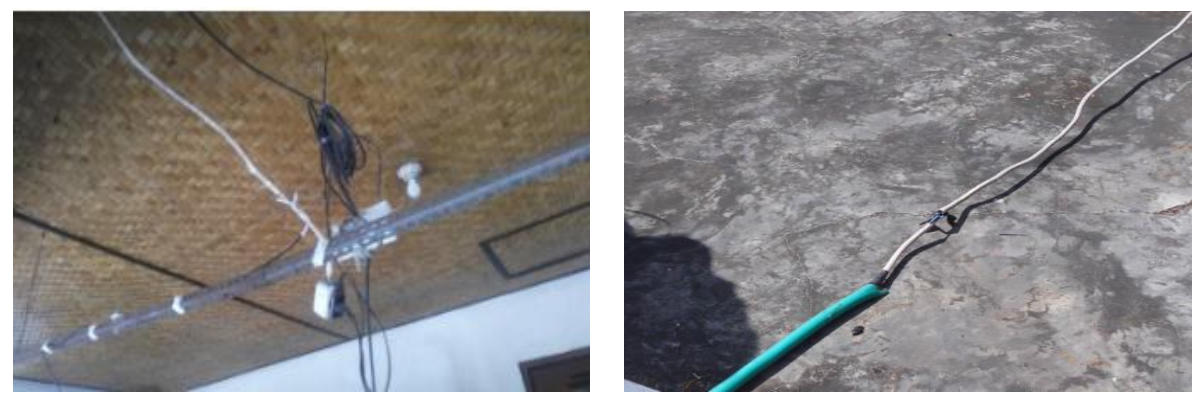

Gambar 2.1. Isolasi sambungan yang berbahaya 
Listrik merupakan kebutuhan yang sangat vital, bahkan sekarang ini listrik menjadi kebutuhan primer bagi penunjang kegiatan manusia. Sumber arus listrik tentu memiliki banyak manfaat bagi kehidupan, bayangkan saja ketika tidak ada manfaat energi listrik yang mengalir di suatu tempat. Pasti tempat itu akan mengalami kesulitan. Karena pada zaman modern ini sangat penting adanya arus listrik. Manfaat listrik sangat banyak terhadap kehidupan jaman modern ini seperti Sebagai penerangan, Tentu dengan adanya sumber arus listrik maka penerangan akan di dapatkan. Penerangan seperti lampu tentu membutuhkan sumber arus listrik sehingga penerangan atau lampu bisa menyala. Dengan adanya penerangan atau lampu tentu dalam melakukan aktivitas kehidupan sehari-hari akan lebih mudah. Sebagai sumber energi, Selain berfungsi sebagai penerangan, fungsi lain dari arus listrik adalah sumber energi. Karena dengan adanya listrik seluruh energi dapat dibangkitkan oleh karen itu listrik sangat penting bagi kehidupan sehari-hari apalagi untuk menunjang aktivitas manusia. Peralatan listrik itu membutuhkan sumber arus listrik untuk menyalakannya, tanpa adanya sumber arus listrik maka peralatan yang demikian itu tidak dapat menyala. Sebagai sumber panas, Listrik bisa dijadikan sebagai penghasil panas, manfaat energi listrik banyak digunakan berbagai macam keperluan rumah tangga. Listrik bisa dijadikan sebagai sumber panas, karena arus litrik bisa mengalir dengan memanfaatkan nikel atau elemen-elemen pemanas yang bisa menghasilkan panas. Panas yang dihasilkan inilah yang digunakan dan juga dibutuhkan dalam kehidupan sehari-hari. Energi listrik yang menghasilkan panas bisa digunakan untuk kompor listrik, penanak nasi dan juga digunakan untuk menyetrika. Semua peralatan tersebut mengubah energi listrik menjadi panas. Sebagai penghasil gerak, Energi listrik yang ada di dalam kehidupan ini juga bisa dihasilkan sebagai penghasil gerak. Banyak kebutuhan rumah tangga yang membutuhkan listrik untuk menggerakkan sesuatu. Misalnya saja energi listrik yang diubah menjadi energi gerak bisa digunakan untuk menggerakkan motor, mobil, kipas angin dan masih banyak lagi lainnya. Saat mengubah energi gerak dibutuhkan arus listrik untuk menggerakkan alatalat tersebut.

Tegangan sentuh bisa terjadi dengan dua cara, cara pertama tangan orang menyentuh langsung kawat beraliran listrik seperti ditunjukan pada gambar 2.2a, dan cara kedua tegangan sentuh tidak langsung, ketika terjadi kerusakan isolasi pada peralatan listrik dan orang menyentuh peralatan listrik tersebut yang bersangkutan akan terkena bahaya tegangan sentuh seperti ditunjukan pada gambar 2.2b. Kerusakan isolasi bisa terjadi pada belitan kawat pada motor listrik, generator atau transformator. Isolasi yang rusak harus diganti karena termasuk kategori kerusakan permanen.

Untuk mencegah bahaya jika terkena tegangan sentuh baik teganan sentuh langsung dan tak langsung dengan perangkat proteksi didalam instalasi listrik yang berfungsi mendeteksi Ketidakseimbangan antara konduktor pengalir arus listrik L (Fasa) dan konduktor kembali (Neutral - 0) seperti ditunjukan pada gambar 2.3. Secara umum perangkat tersebut disebut dengan RCD (residual Current Device).

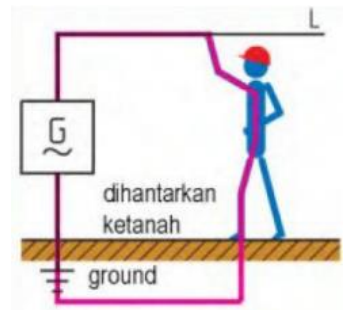

Gambar 2.2a. Sentuh Langsung

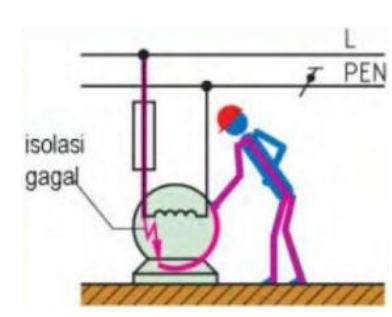

Gambar 2.2b. Sentuh tak langsung 

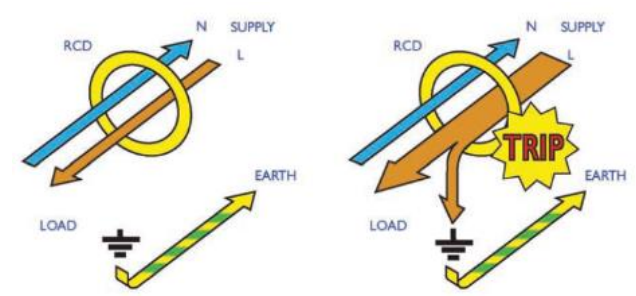

Gambar 2.3. Prinsip kerja RCD (residual Current Device)

RCD ini akan segera memutuskan aliran Arus listrik (Trip) jika ada kebocoran arus listrik ke perangkat lain atau ke bumi. RCD memonitor jumlah arus listrik yang mengalir melalui kabel fasa dan kembali melalui kabel netral. Besaran arus yang datang dan kembali haruslah seimbang, jika terdapat arus bocor karena kesalahan/kerusakan ketidakseimbangan terdeteksi oleh RCD dan segera memutus arus listriknya (trip) sebelum kerusakan atau cedera terjadi.

Kebocoran arus listrik melewati tubuh seseorang merupakan salah satu insiden yang kita kenal tersengat listrik atau tersetrum. Alat ini berfungsi segera memutuskan jika arus listrik melewati tubuh seseorang, seperti ditunjukan pada gambar 2.4. Alat ini bukan menghilangkan resiko tersengat listrik sama sekali, tetapi mencegah sesegera mungkin (dibawah 1 detik - millisecond), jangan sampai arus listrik yang mengalir membahayakan.

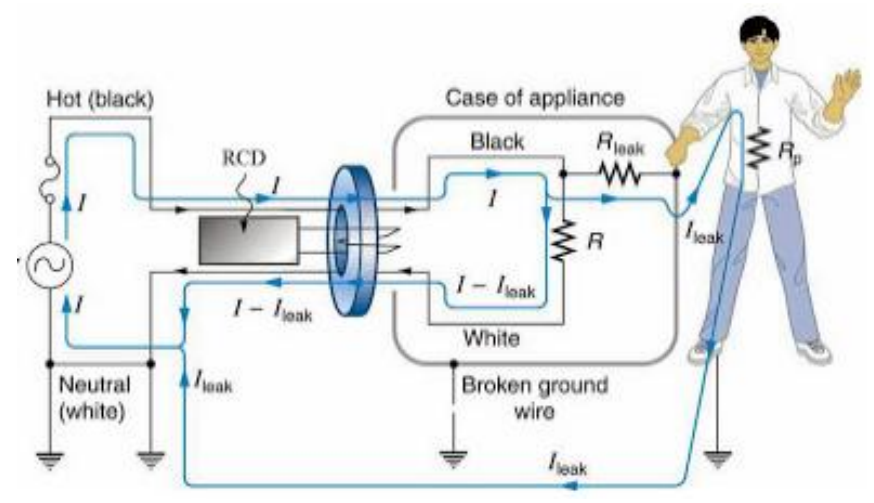

Gambar 2.4. Sistem kerja RCD jika ada arus yang mengalir ke tubuh manusia

RCD yang didesain untuk memberi perlindungan dari tersengat listrik yang bisa memutuskan listrik dalam waktu yang sangat singkat $(200-40 \mathrm{~ms}, \mathrm{~ms}=1 / 1000$ detik), menjaga agar resiko tidak sampai taraf berbahaya. Perlindungan dengan RCD bisa membantu menyelamatkan seseorang dari resiko kecelakaan fatal karena tersengat listrik. RCD tidak bisa menerima insiden hubung singkat, karena itu harus dilengkapi serta MCB sebagai proteksi beban berlebih dan short circuit.

Penghantar/Kabel merupakan penyalur energi listrik. Pemilihan kabel sangat berpengaruh terhadap daya listrik dan perlindungan/isolasi terhadap arus bocor yang bisa menyebabkan bahaya arus listrik. Arus Listrik adalah mengalirnya elektron secara terus menerus dan berkesinambungan pada konduktor akibat perbedaan jumlah elektron pada beberapa lokasi yang jumlah elektronnya tidak sama. satuan arus listrik adalah Ampere.

Kabel listrik NYA, NYM dan NYY ini merupakan tata nama atau nomenklatur pada kabel. PUIL 2011 (Persyaratan Umum Instalasi Listrik tahun 2011) dalam lampiran C dijelaskan mengenai tata nama (nomenklatur) kabel ini. Dari lampiran tersebut, kabel NYA, NYM dan NYY berarti kabel standar berpenghantar tembaga ("N") dengan isolasi dan selubung dari PVC ("Y"). Jenis kabel NYA, NYM dan NYY ditunjukan pada gambar 2.5. 

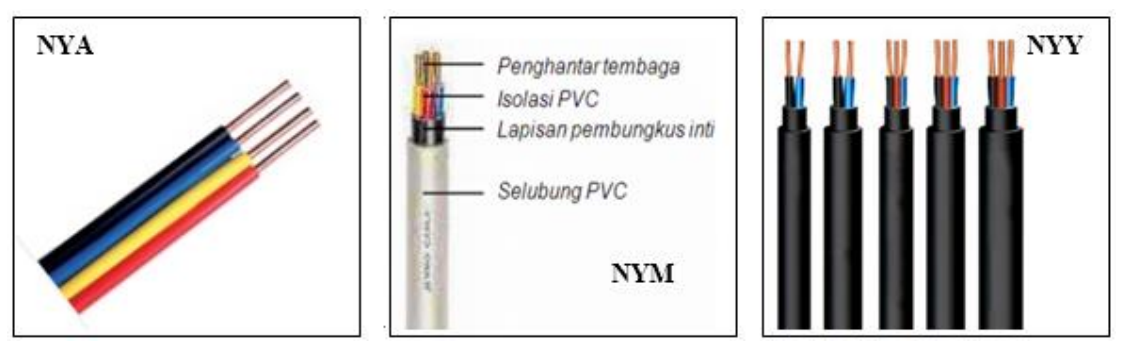

Gambar 2.5. Jenis kabel Arus Kuat

Metode Pelatihan Pengaman Instalasi Listrik Sesuai Persyaratan Umum Instalasi Listrik 2011 Serta Amandemen 2014 Di Desa Sinduwati, Kecamatan Sidemen-Karangasem. Oleh karena itu, dilaksanakan kerangka pemecahan masalah secara operasional sebagai berikut.

1. Penyelenggaraan pelatihan intensif tentang:

a. Bahaya-bahaya instalasi listrik;

b. Pemakaian energi listrik secara aman dan benar;

c. Pemilihan peralatan pengaman yang sesuai dengan peralatan yang diamankan;

d. Pemilihan kabel/Penghantar untuk penempatan pemasangan dalam instalasi listrik.

2. Implementasi Pemasangan kabel tanam untuk instalasi listrik untuk menyalurkan energi dengan benar dan aman dengan cara:

a. Teknik mengidentifikasi, memilih, dan merumuskan peralatan listrik yang akan digunakan sebagai instalasi kabel tanam;

b. Teknologi isolasi kabel/ penghantar dalam mengamankan bahaya kebocoran arus listrik;

c. Cara pemilihan Peralatan Instalasi listrik yang benar untuk digunakan dalam mengamankan peralatan dan lingkungan;

d. Teknik pemasangan dan penyambungan kabel tanam untuk instalasi daya dan penerangan;

e. Informasi Teknik Pelatihan Dasar Pemasangan Peralatan Instalasi listrik.

\section{HASIL DAN PEMBAHASAN}

Pelaksanaan kegiatan Hibah Udayana Mengabdi "Pelatihan Pengaman Instalasi Listrik Sesuai Persyaratan Umum Instalasi Listrik 2011 Serta Amandemen 2014 Di Desa Sinduwati, Kecamatan Sidemen-Karangasem" dengan pengenalan peralatan-peralatan instalasi listrik, pengaman Arus Bocor dengan ELCB, pengaman Arus lebih dengan MCB, lampu hemat energi (lampu LED), peserta pengabdian juga dipersilahkan untuk melihat-lihat dan mempraktekkan, sehingga mereka bisa mendapatkan pemahaman yang lebih banyak tentang peralatan yang sesuai dengan standar SNI-LMK. Foto kegiatan dan Peralatan Instalasi listrik (Kabel NYM dan NYY serta Pembatas arus $\mathrm{MCB}$ ) ditunjukan pada gambar 3.1
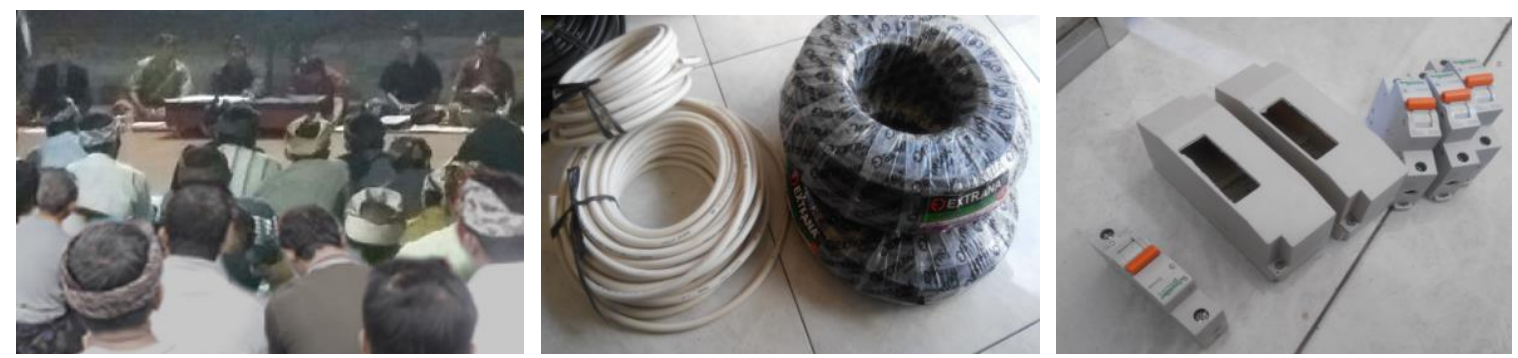

Gambar 3.1. kegiatan dan Peralatan Instalasi listrik 
Setelah dilakukan kegiatan Pengabdian Kepada Masyarakat tentang Pelatihan Pengaman Instalasi Listrik Sesuai Persyaratan Umum Instalasi Listrik 2011 serta Amandemen 2014 Di Desa Sinduwati, Kecamatan Sidemen-Karangasem, hasil yang didapatkan adalah sebagai berikut:

1. Di Desa Sinduwati, Kecamatan Sidemen-Karangasem telah mendapatkan pengetahuan dasardasar instalasi listrik yang sesuai dengan Persyaratan Umum Instalasi Listrik (PUIL) 2011 serta Amandemen 2014.

2. Banyak permasalahn-permasalahan yang ada di masyarakat desa Sinduwati untuk masalah pemilihan dan pemasangan instalasi listrik, dan masalah ini sudah diberikan pengetahuan dasar tentang bahaya-bahaya yang ditimbulkan jika terkena arus listrik / kesetrum. Pemilihan, perawatan dan pemasangan instalasi listrik yang benar dan aman telah disampaikan kepada masyarakat, sehingga masyarakat dapat segera mengaplikasikan.

3. Team Pengabdian Kepada Masyarakat mendapatkan pengalaman langsung dan terjun langsung berhadapan dengan masyarakat untuk menerapkan instalasi kelistrikan yang sesuai dengan PUIL 2011 serta Amandemen 2014.

\section{KESIMPULAN DAN SARAN}

\section{1. Simpulan}

Simpulan yang didapat dari kegiatan pengabdian masrakat tentang Pelatihan Pengaman Instalasi Listrik Sesuai Persyaratan Umum Instalasi Listrik 2011 Serta Amandemen 2014 di Desa Sinduwati, Kecamatan Sidemen-Karangasem sebagai berikut:

1. Pemberian pengetahuan dasar-dasar pemilihan peralatan instalasi listrik yang benar dan aman bagi seluruh masyarakat sangat diperlukan, sehingga masyarakat dapat menggunakan sesuai dengan peruntukannya.

2. Khusus di desa Sinduwati, Kecamatan Sidemen-Karangasem, masih banyak dijumpai pemakaian peralatan dan pemasangan instalasi listrik yang tidak memenuhi standar dan berbahaya bagi manusia dan lingkungannya.

\subsection{Saran}

Saran yang bisa diberikan dari kegiatan pengabdian kepada masyarakat di di Desa Sinduwati, Kecamatan Sidemen-Karangasem adalah segera mengecek dan memperbaiki instalasi yang bermasalah, seperti menambah/mengganti isolasi kabel, merapikan/merawat/ mengganti kabel dan peralatan lainnya yang kurang bagus.

\section{UCAPAN TERIMA KASIH}

Penulis mengucapkan terimakasih kepada Universitas Udayana atas dukungan yang diberikan melalui Hibah Pengabdian kepada Masyarakat Tahun 2017 dengan Surat Perjanjian Penugasan dalam Rangka Pelaksanaan Hibah Pengabdian Kepada Masyarakat Udayana Mengabdi dengan Nomor: No: 647 58/UN14.4.A/PM/2017, Tanggal 12 Juli 2017.

\section{DAFTAR PUSTAKA}

A.E. Fitzgerald,SC.D.(1983), Dasar-dasar Elektro Teknik. Northeastern University.

Badan Standarisari Nasional (2011), Persyaratan Umum Instalasi Listrik 2011 (PUIL 2011), SNI 0225:2011, Jakarta, BSN

Badan Standarisari Nasional (2014), Persyaratan Umum Instalasi Listrik 2011 (PUIL 2011), SNI 0225:2011 / Amd2:2014, Amandemen 2:2014 (IEC 60364-4-42:2010, MOD), Jakarta, BSN

P. Van. Harten., E. (1983), Instalasi Listrik Arus Kuat 1, 2 dan 3 , CV Trimitra Mandiri, Jakarta 